\title{
Two cases of airport-associated falciparum malaria in Frankfurt am Main, Germany, October 2019
}

\author{
Imke Wieters ${ }^{1,2}$, Philip Eisermann ${ }^{2,3}$, Frauke Borgans ${ }^{1}$, Katharina Giesbrecht ${ }^{1}$, Udo Goetsch4, Gudrun Just-Nübling ${ }^{1}$, Johanna \\ Kessel $^{1}$, Simone Lieberknecht ${ }^{1}$, Birgit Muntau ${ }^{3}$, Dennis Tappe ${ }^{3}$, Joscha Schork ${ }^{4,5}$, Timo Wolf ${ }^{1,5}$ \\ 1. Infectious Diseases, Department of Internal Medicine II, University Hospital Frankfurt, Frankfurt am Main, Germany \\ 2. These authors contributed equally to this work and share first authorship \\ 3. National Reference Centre for Tropical Pathogens, Bernhard Nocht Institute for Tropical Medicine, Hamburg, Germany \\ 4. Municipal Health Protection Authority, Frankfurt am Main, Germany \\ 5. These authors contributed equally to this work and share last authorship
}

Correspondence: Timo Wolf (Timo.Wolf@kgu.de)

Two cases of presumably airport-acquired falciparum malaria were diagnosed in Frankfurt in October 2019. They were associated with occupation at the airport, and Plasmodium falciparum parasites from their blood showed genetically identical microsatellite and allele patterns. Both had severe malaria. It took more than a week before the diagnosis was made. If symptoms are indicative and there is a plausible exposure, malaria should be considered even if patients have not travelled to an endemic area.

Here, we report two cases of malaria that have been diagnosed outside an endemic area. Both cases occurred in conjunction with occupation at an airport, indicating that a vector-competent mosquito was imported by air traffic. The parasites found in both cases were found to have shown genetically identical microsatellite and allele patterns.

\section{Case 1}

On 5 October 2019, a 38-year-old man with a positive rapid diagnostic test result for malaria was transferred to the emergency department of University Hospital Frankfurt, Germany, from a local general hospital. He had been found at home with fever, diarrhoea and confusion on the same day. The patient later reported a history of fever and malaise starting on 27 September. Plasmodium falciparum with a parasitaemia of $7 \%$ was demonstrated microscopically (Figure 1). Creatinine was elevated to $1.84 \mathrm{mg} / \mathrm{dL}$ (norm: max $1.2 \mathrm{mg} / \mathrm{dL}$ ), but there were no other clinical signs or laboratory markers of severe malaria. He was treated with five doses of artesunate $2.4 \mathrm{mg} / \mathrm{kg}$ intravenously and received oral follow-up treatment with atovaquone/ proguanil (1,00omg/40omg per day) for 3 days and recovered fully. He was discharged from hospital after 12 days and has since remained free of symptoms for 47 days.
The patient had no recent travel history, however, he had travelled to Morocco in April 2019. He did not report any underlying illness. He works at Frankfurt Airport in aircraft maintenance, and recalled that he had experienced multiple insect bites during a nightshift 2 weeks before the onset of symptoms. He had not received any blood transfusions in the past.

\section{Case 2}

Case 2, a 51-year-old male, was transferred to the University Hospital Frankfurt on 9 October 2019 with the diagnosis of falciparium malaria and a parasitaemia of $25 \%$. He had travelled to Algeria on 27 September, while already suffering from headache and myalgia, which he thought was an influenza-like illness. In Algeria, he visited a local doctor on 30 September when he noticed he had a fever of $38^{\circ} \mathrm{C}$. Malaria was diagnosed on 6 October, 3 days after Patient 2 presented to a hospital in Algeria. He was awake but had signs of circulatory shock with a blood pressure of $60 / 40 \mathrm{mmHG}$ and a heart rate of 115 per minute, so that he required fluid resuscitation. He was treated with quinine $16 \mathrm{mg} / \mathrm{kg}$ intravenously as loading dose and a second maintenance dose of $16 \mathrm{mg} / \mathrm{kg} 4$ hours later. On 8 October, he was transferred by air to a local general hospital in Frankfurt/Main. Upon arrival, the patient's condition deteriorated rapidly, reaching a Glasgow-Coma-Scale of three and he was mechanically ventilated. A cerebral computer tomography (CT) scan showed signs of cerebral swelling without necessity for neurosurgical intervention and acute kidney failure occurred (creatinine $2.16 \mathrm{mg} / \mathrm{dL}$, norm: $\max 1.2 \mathrm{mg} / \mathrm{dL}$; urea $199 \mathrm{mg} /$ $\mathrm{dL}$, norm: $\max 55 \mathrm{mg} / \mathrm{dL}$ ). The patient was transferred to the University Hospital Frankfurt the next morning and treatment was continued with five doses of artesunate $2.4 \mathrm{mg} / \mathrm{kg}$ intravenously and oral follow-up treatment with atovaquone/proguanil $(1,000 \mathrm{mg} / 400 \mathrm{mg}$ per day) for 3 days. He made a full recovery after 16 days of 


\section{FIgURE 1}

Giemsa stain of Plasmodium falciparum trophozoites at a parasite density of $7 \%$, case of airport-acquired falciparum malaria, Frankfurt, Germany, October 2019 (Case 1, magnification $\mathrm{x} 1,000$ )

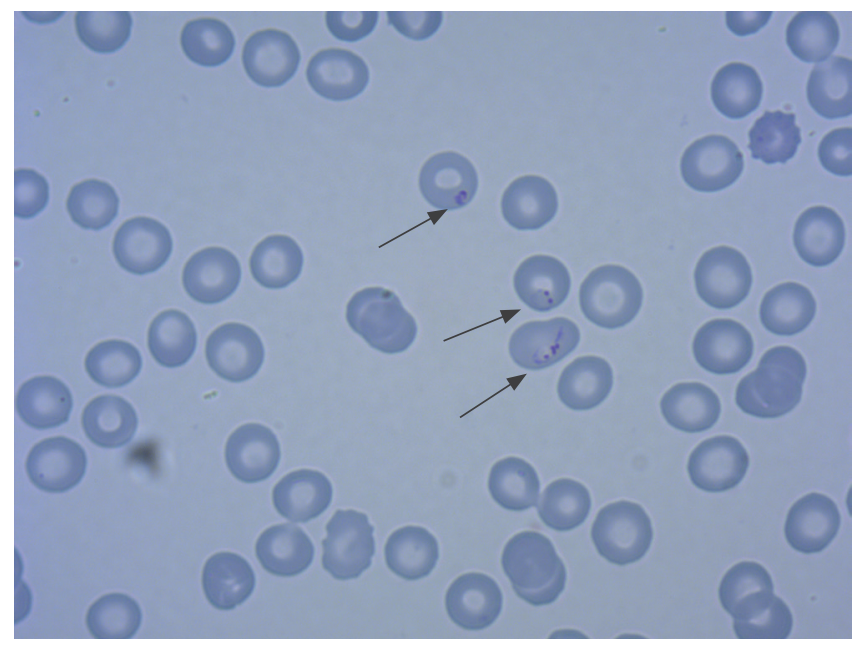

inpatient treatment. Until 40 days after discharge, he remained well and free of symptoms.

Similarly to case 1 , he did not have any history of recent travel to malaria endemic areas, nor had he previously had blood transfusions or underlying illnesses. He was also working at Frankfurt Airport, and on the same night shift as Case 1 but he did not recall any insect bites.

\section{Genotyping of Plasmodium falciparum from patient blood samples}

An autochthonous infection with $P$. falciparum was suspected in both patients and whole blood samples were sent to the National Reference Centre for Tropical Pathogens at the Bernhard Nocht Institute for Tropical Medicine (BNITM) in Hamburg, Germany. In order to identify possible clonality of the two $P$. falciparum strains, we used polymerase chain reaction (PCR)based parasite typing targeting the microsatellite PfRRM of the rif gene family [1], the Duffy-Binding-Like domain a (DBLa) of the var gene family [2] and the genes encoding for two merozoite surface proteins (MSP-1 and MSP-2) [3]. The markers PfRRM, DBLa and MSP-1 as well as MSP-2 contain highly polymorphic regions that can be used to differentiate between individual $P$. falciparum strains. Fragment length analysis was performed using the 3130 XL Genetic Analyzer with GeneMapper analyser software version 4.1 (Applied Biosystems, Waltham, MA, USA).

Genetic typing of the two samples showed identical DNA patterns for PfRRM and DBLa respectively (Figure 2). Furthermore, MSP-1 and MSP-2 allele fragment lengths were shown to be identical as well (Table). In comparison, three randomly selected samples taken from the archive of the BNITM revealed different individual patterns (Figure 2, Table).

\section{Environmental risk assessment and vector control}

On 11 October 2019, the public health authority of the city of Frankfurt contacted the employer of the patients and the airline responsible for the service hall. A list of people who worked in this aircraft service hall during the previous 4 weeks and who were on sick leave was provided; nine people were identified and contacted by phone. One of them reported mosquito bites approximately 10 days prior to the interview, but none had any symptoms of malaria.

The airline confirmed the presence of airplanes returning from three falciparum malaria endemic countries in sub-Saharan Africa in the service hall in which both patients had worked during 21 days before the symptom onset (27 September). During this period, one of them noticed mosquito bites. Considering the day temperatures of more than $20^{\circ} \mathrm{C}$ during the time of likely exposure, company rooms, the aircraft service hall and the surrounding areas were inspected for possible mosquito breeding sites. No stagnant water as a possible source of reproduction of (imported) Anopheles mosquitoes was found. There were no further cases of malaria in the following 2 weeks in the region. The Robert Koch Institute (the national public health institute in Berlin) was asked to screen all infectious disease notifications in the Frankfurt Airport region for malaria cases without a travel history to endemic areas between 25 August and 20 October. None was reported.

\section{Discussion}

Here we describe two cases of falciparum malaria that were presumed to have been acquired at Frankfurt Airport. While 896 imported malaria cases to Germany were reported in 2018 [4] there have been no reported, autochthonous cases. Morocco and Algeria have been declared free of malaria in 2010 and 2019 respectively [5]. In Europe, autochthonous transmissions have been described in close proximity to airports as the likely source of infection [6-15] in Belgium, France, Italy, Spain and Switzerland.

To our knowledge, there were no previously documented cases $P$. falciparum infections in employees of an airport in a non-endemic country that were found to be genetically identical. The simultaneous onset of symptoms also suggests a common source of the infections. P. falciparum strains in the two cases showed identical allele and microsatellite patterns using PCRbased fingerprinting. In our opinion, the autochthonous transmission of malaria parasites in central Europe remains highly unlikely. In the two severely ill cases described here, the time from symptom onset until the final diagnosis was long ( 9 and 12 days), a fact which has also been previously reported in airport malaria $[13,14]$. This circumstance demonstrates that it is crucial to consider malaria in patients who have not 


\section{FIGURE 2}

Parasite typing targeting (A) the multicopy microsatellite PfRRM and (B) the Duffy-Binding-Like domain a (DBLa) of Plasmodium falciparum, cases of airport-acquired malaria, Frankfurt/Main, Germany October 2019

\section{A. The multicopy microsatellite PfRRM}
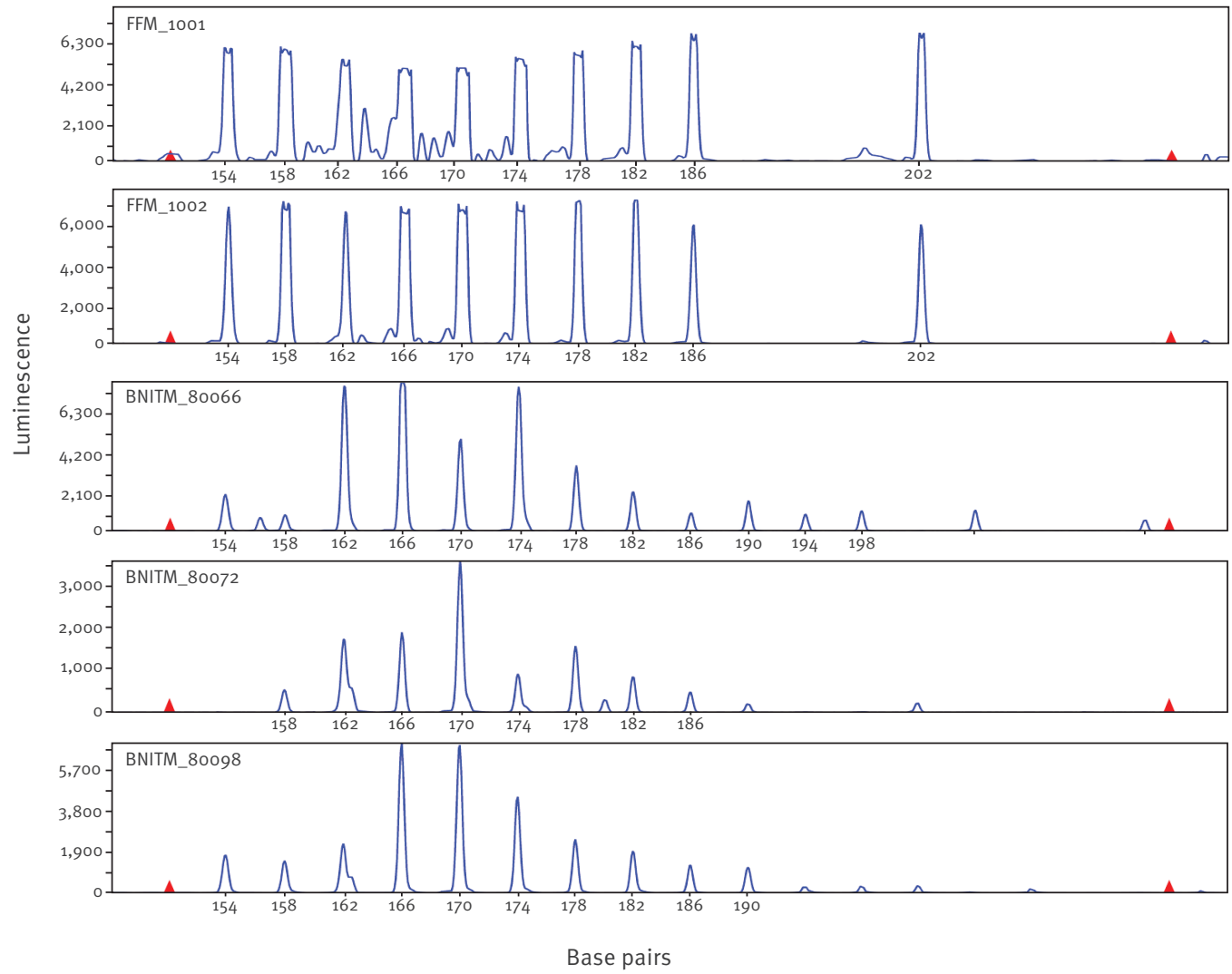

B. The Duffy-Binding-Like domain a (DBLa)
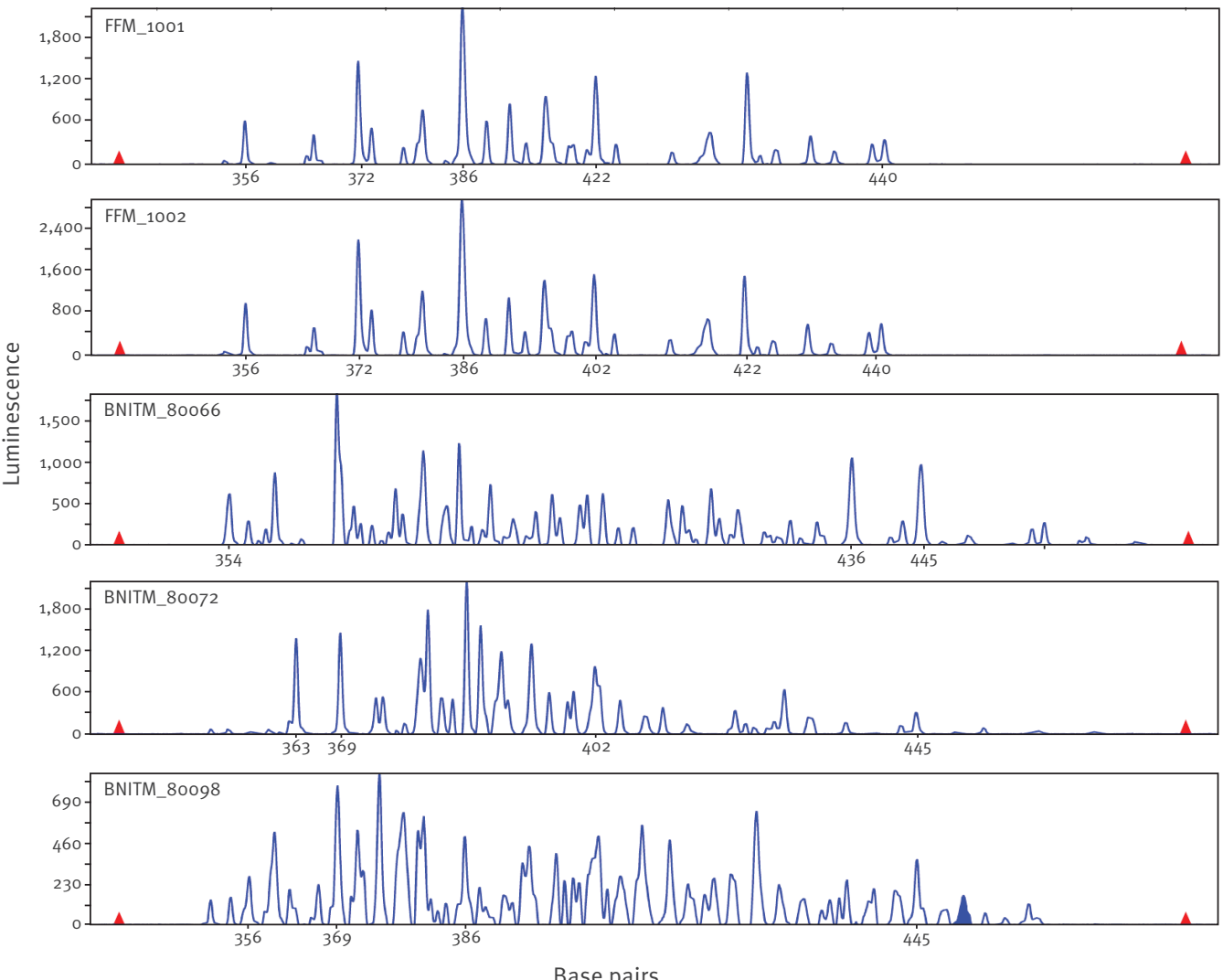

a Analysis was performed on whole blood samples of both patients (FFM 1001; FFM 11002) and three samples of unrelated infections with P. falciparum. 
MSP-1 and MSP-2 allele distribution in isolates from two cases of airport-acquired falciparum malaria ${ }^{\text {a }}$ compared to three unrelated Plasmodium falciparum infections, Frankfurt, Germany, October 2019

\begin{tabular}{|c|c|c|c|c|c|c|}
\hline \multicolumn{7}{|l|}{ MSP-1 } \\
\hline & \multirow{2}{*}{ Allelic family } & \multicolumn{5}{|c|}{ Allele (size, bp) ${ }^{\mathrm{b}}$} \\
\hline & & 1 & 2 & 3 & 4 & 5 \\
\hline FFM_1001 & \multirow{5}{*}{ K1 } & 185 & $n / d$ & $\mathrm{n} / \mathrm{d}$ & $\mathrm{n} / \mathrm{d}$ & $\mathrm{n} / \mathrm{d}$ \\
\hline FFM_1002 & & 185 & $n / d$ & $\mathrm{n} / \mathrm{d}$ & $n / d$ & $n / d$ \\
\hline BNITM_80066 & & 129 & 158 & 185 & 194 & 203 \\
\hline BNITM_80072 & & 158 & 168 & 194 & 203 & 221 \\
\hline BNITM_80098 & & 158 & 168 & 177 & 185 & 194 \\
\hline FFM_1001 & \multirow{5}{*}{ MAD20 } & $\mathrm{n} / \mathrm{d}$ & $\mathrm{n} / \mathrm{d}$ & $\mathrm{n} / \mathrm{d}$ & $\mathrm{n} / \mathrm{d}$ & $\mathrm{n} / \mathrm{d}$ \\
\hline FFM_1002 & & $\mathrm{n} / \mathrm{d}$ & $n / d$ & $\mathrm{n} / \mathrm{d}$ & $n / d$ & $\mathrm{n} / \mathrm{d}$ \\
\hline BNITM_80066 & & 102 & 110 & 120 & 167 & 194 \\
\hline BNITM_80072 & & 131 & 139 & $\mathrm{n} / \mathrm{d}$ & $n / d$ & $\mathrm{n} / \mathrm{d}$ \\
\hline BNITM_80098 & & 102 & 120 & 158 & $\mathrm{n} / \mathrm{d}$ & $\mathrm{n} / \mathrm{d}$ \\
\hline FFM_1001 & \multirow{5}{*}{ R033 } & $\mathrm{n} / \mathrm{d}$ & $\mathrm{n} / \mathrm{d}$ & $\mathrm{n} / \mathrm{d}$ & $\mathrm{n} / \mathrm{d}$ & $\mathrm{n} / \mathrm{d}$ \\
\hline FFM_1002 & & $\mathrm{n} / \mathrm{d}$ & $\mathrm{n} / \mathrm{d}$ & $\mathrm{n} / \mathrm{d}$ & $n / d$ & $\mathrm{n} / \mathrm{d}$ \\
\hline BNITM_80066 & & 125 & 130 & $\mathrm{n} / \mathrm{d}$ & $n / d$ & $\mathrm{n} / \mathrm{d}$ \\
\hline BNITM_80072 & & 125 & 130 & $\mathrm{n} / \mathrm{d}$ & $\mathrm{n} / \mathrm{d}$ & $\mathrm{n} / \mathrm{d}$ \\
\hline BNITM_80098 & & 125 & 130 & $\mathrm{n} / \mathrm{d}$ & $n / d$ & $\mathrm{n} / \mathrm{d}$ \\
\hline \multicolumn{7}{|l|}{ MSP-2 } \\
\hline FFM_1001 & \multirow{5}{*}{$3 D_{7}$} & 253 & 265 & $\mathrm{n} / \mathrm{d}$ & $\mathrm{n} / \mathrm{d}$ & $\mathrm{n} / \mathrm{d}$ \\
\hline FFM_1002 & & 253 & 265 & $\mathrm{n} / \mathrm{d}$ & $n / d$ & $\mathrm{n} / \mathrm{d}$ \\
\hline BNITM_80066 & & 253 & 265 & $\mathrm{n} / \mathrm{d}$ & $\mathrm{n} / \mathrm{d}$ & $\mathrm{n} / \mathrm{d}$ \\
\hline BNITM_80072 & & 253 & 265 & $\mathrm{n} / \mathrm{d}$ & $n / d$ & $\mathrm{n} / \mathrm{d}$ \\
\hline BNITM_80098 & & 253 & 265 & $\mathrm{n} / \mathrm{d}$ & $\mathrm{n} / \mathrm{d}$ & $\mathrm{n} / \mathrm{d}$ \\
\hline FFM_1001 & \multirow{5}{*}{$\mathrm{FC} 27$} & 205 & $\mathrm{n} / \mathrm{d}$ & $\mathrm{n} / \mathrm{d}$ & $\mathrm{n} / \mathrm{d}$ & $\mathrm{n} / \mathrm{d}$ \\
\hline FFM_1002 & & 205 & $\mathrm{n} / \mathrm{d}$ & $\mathrm{n} / \mathrm{d}$ & $\mathrm{n} / \mathrm{d}$ & $\mathrm{n} / \mathrm{d}$ \\
\hline BNITM_80066 & & 288 & 302 & $\mathrm{n} / \mathrm{d}$ & $n / d$ & $\mathrm{n} / \mathrm{d}$ \\
\hline BNITM_80072 & & 288 & 302 & $\mathrm{n} / \mathrm{d}$ & $\mathrm{n} / \mathrm{d}$ & $\mathrm{n} / \mathrm{d}$ \\
\hline BNITM_80098 & & 288 & 302 & $n / d$ & $n / d$ & $n / d$ \\
\hline
\end{tabular}

Bp: base pair; $\mathrm{n} / \mathrm{d}$ : no allele detected.

a FFM_1001; FFM_11002.

${ }^{b}$ Different alleles within an allelic family were identified according to their size and listed numerically.

visited an endemic area, as a differential diagnosis if the clinical symptoms are coherent and there is a plausible mode of exposure, e.g. in the vicinity of an international airport with intercontinental flights.

Indigenous Anopheles species (e.g. A. plumbeus) showed susceptibility for $P$. falciparum in experimental infections but no natural parasite transmission has been proven so far $[16,17]$. In two German cases of autochthonous malaria, a local nosocomial transmission by $A$. plumbeus was suspected, however [18]. We did not have access to data concerning the mosquito monitoring for specific geographic areas in Germany nor to data for populations of indigenous or imported Anopheles species in the specific region around Frankfurt. The population of $A$. plumbeus in the Frankfurt area is thought to be small [19]. In the described cases, the transmission of $P$. falciparum by an infected imported mosquito seems to be highly likely. Considering sporadic reports of autochthonous malaria especially in southern Europe in the last years [20], it is important to investigate cases epidemiologically, parasitologically and entomologically, in order to distinguish so-called airport malaria as described here from transmission events originating from autochthonous mosquitoes.

\section{Conflict of interest}

None declared.

\section{Authors' contributions}

IW, TW analysed clinical samples, treated the patient and wrote the manuscript.

PE analysed the samples and wrote the manuscript.

JS collected epidemiological data and wrote the manuscript.

DT analysed the samples and assisted in writing the manuscript.

UG collected epidemiological data and assisted in writing the manuscript.

KG, FB, GJN, SL, JK treated the patients and assisted in writing the manuscript.

BM performed laboratory analysis and contributed to writing the manuscript in the revision stage.

All authors searched relevant literature.

\section{References}

1. Su XZ, Carucci DJ, Wellems TE. Plasmodium falciparum: parasite typing by using a multicopy microsatellite marker, PfRRM. Exp Parasitol. 1998;89(2):262-5. https://doi. org/10.1006/expr.1998.4299 PMID: 9635451

2. Taylor HM, Kyes SA, Harris D, Kriek N, Newbold Cl. A study of var gene transcription in vitro using universal var gene primers. Mol Biochem Parasitol. 2000;105(1):13-23. https:// doi.org/10.1016/S0166-6851(99)00159-o PMID: 10613695

3. Robert F, Ntoumi F, Angel G, Candito D, Rogier C, Fandeur T, et al. Extensive genetic diversity of Plasmodium falciparum isolates collected from patients with severe malaria in Dakar, Senegal. Trans R Soc Trop Med Hyg. 1996;90(6):70411. https://doi.org/10.1016/S0035-9203(96)90446-0 PMID: 9015525

4. Robert Koch-Institut (RKI). Infektionsepidemiologisches Jahrbuch meldepflichtiger Krankheiten für 2018. [Annual epidemiological report of notifiable infections for 2018]. Berlin: RKI. [Accessed 31 Oct 2019]. German. Available from: https:// www.rki.de/DE/Content/Infekt/Jahrbuch/Jahrbuch_2018. pdf?__blob=publicationFile

5. World Health Organization (WHO). The E-2020 initiative of 21 malaria-eliminating countries: 2019 progress report. Geneva: WHO; 2019. Available from: https://apps.who.int/iris/ bitstream/handle/10665/325304/WHO-CDS-GMP-2019.07-eng. pdf?ua $=1$

6. Pomares-Estran C, Delaunay P, Mottard A, Cua E, Roger PM, Pradines B, et al. Atypical aetiology of a conjugal fever: autochthonous airport malaria between Paris and French Riviera: a case report. Malar J. 2009;8(1):202. https://doi. org/10.1186/1475-2875-8-202 PMID: 19698152

7. Queyriaux B, Pradines B, Hasseine L, Coste S, Rodriguez P, Coffinet T, et al. Airport malaria. Presse Med. 2009;38(78):1106-9. https://doi.org/10.1016/j.lpm.2008.11.014 PMID: 19282131 
8. Siala E, Gamara D, Kallel K, Daaboub J, Zouiten F, Houzé S, et al. Airport malaria: report of four cases in Tunisia. Malar J. 2015;14(1):42. https://doi.org/10.1186/s12936-015-0566-x PMID: 25626591

9. Velasco E, Gomez-Barroso D, Varela C, Diaz O, Cano R. Nonimported malaria in non-endemic countries: a review of cases in Spain. Malar J. 2017;16(1):260. https://doi.org/10.1186/ S12936-017-1915-8 PMID: 28662650

10. Gallien S, Taieb F, Hamane S, De Castro N, Molina JM. Autochthonous falciparum malaria possibly transmitted by luggage-carried vector in Paris, France, February 2013. Euro Surveill. 2013;18(40):20600. https://doi.org/10.2807/15607917.ES2013.18.40.20600 PMID: 24128697

11. Van den Ende I, Lynen L, Elsen P, Colebunders R, Demey $H$, Depraetere K, et al. A cluster of airport malaria in Belgium in 1995. Acta Clin Belg. 1998;53(4):259-63. https://doi.org/10.10 80/17843286.1998.11772033 PMID: 9795446

12. Majori G, Gradoni L, Gianzi FP, Carboni P, Cioppi A, Aureli $\mathrm{G}$. Two imported malaria cases from Switzerland. Trop Med Parasitol. 1990;41(4):439-40. PMID: 2075391

13. Bouvier M, Pittet D, Loutan L, Starobinski M. [Airport malaria: mini-epidemic in Switzerland]. Schweiz Med Wochenschr. 1990;120(34):1217-22. PMID: 2218443

14. Giacomini T, Axler O, Mouchet J, Lebrin P, Carlioz R, Paugam B, et al. Pitfalls in the diagnosis of airport malaria. Seven cases observed in the Paris area in 1994. Scand J Infect Dis. 1997;29(4):433-5. https://doi. org/10.3109/00365549709011848 PMID: 9360267

15. Giacomini T, Mouchet J, Mathieu P, Petithory JC. [Study of 6 cases of malaria acquired near Roissy-Charles-de-Gaulle in 1994. Necessary prevention measures in airports]. Bull Acad Natl Med. 1995;179(2):335-51, discussion 351-3. PMID: 7614062

16. Marchant P, Eling W, van Gemert GJ, Leake CJ, Curtis CF. Could british mosquitoes transmit falciparum malaria? Parasitol Today. 1998;14(9):344-5. https://doi.org/10.1016/S01694758(98)01274-5 PMID: 17040812

17. Schaffner F, Thiéry I, Kaufmann C, Zettor A, Lengeler C, Mathis $A$, et al. Anopheles plumbeus (Diptera: Culicidae) in Europe: a mere nuisance mosquito or potential malaria vector? Malar J. 2012;11(1):393. https://doi.org/10.1186/1475-2875-11-393 PMID: 23181931

18. Krüger A, Rech A, Su XZ, Tannich E. Two cases of autochthonous Plasmodium falciparum malaria in Germany with evidence for local transmission by indigenous Anopheles plumbeus. Trop Med Int Health. 2001;6(12):983-5. https://doi. org/10.1046/j.1365-3156.2001.00816.x PMID: 11737834

19. Stechmücken-Monitoring in Deutschland (CuliMo).

Schlussbericht zum Projekt. [Mosquito monitoring in Germany (CuliMo): final project report]. Duration: 01.05.2015-31.12.2018. Friedrich-Löffler-Institut; 2019. German. Available from: https://www.tib.eu/en/search/id/TIBKAT\%3A1677723092/

20. European Centre for Disease Prevention and Control (ECDC). Epidemiological update - indigenous Plasmodium falciparum malaria cases in the Apulia region, Italy. Stockholm: ECDC; 6 Oct 2017. Available from: https://www.ecdc.europa.eu/en/ news-events/epidemiological-update-indigenous-plasmodiumfalciparum-malaria-cases-apulia-region

\section{License, supplementary material and copyright}

This is an open-access article distributed under the terms of the Creative Commons Attribution (CC BY 4.0) Licence. You may share and adapt the material, but must give appropriate credit to the source, provide a link to the licence and indicate if changes were made.

Any supplementary material referenced in the article can be found in the online version.

This article is copyright of the authors or their affiliated institutions, 2019. 